\title{
Why it's never too late to start a plan for retirement
}

\author{
Stephen Barry, Senior Financial Consultant for Wesleyan Financial Services, shares insights on \\ the common areas that are best to focus on in order to reach your retirement goal.
}

The earlier you start financial planning the better. However, with the demands of managing a busy working and personal life, this is something that can understandably be neglected.

The current market climate is unstable due to COVID-19, and this is impacting on savings, mortgage rates and investments returns. Over the past 12 months we have seen an increasing number of dentists who are considering their exit strategy from the profession and have sought help in assessing and understanding their position, to see if their existing retirement provisions are on track.

Here are a couple of areas to consider when thinking about your retirement planning and some financial opportunities to help you reach your goal:

\section{Think about what you're going to need}

Giving yourself time to sit down and think about what you want your retirement years to look like, when you want to retire and what provisions you have in place already is key to a retirement plan. It may not seem the most exciting task but the reward when you get it right may move you closer towards your retirement aspirations in a timeframe sooner than you thought possible.

You might consider that you won't be living the exact same lifestyle as you do now. Currently, you may still be supporting your children with their university costs or paying off your mortgage. How will any changes in these circumstances impact your income and capital in retirement? Remember that a pension income should cover your basic needs - anything over and above that could allow you more financial freedom in retirement.

\section{Shop around}

There are many options available to you when it comes to utilising your money purchase pension savings in retirement. For example, you could use them to buy an annuity, which is a regular guaranteed income payable for life. Annuities are usually provided by an insurance company.

If you decide to buy an annuity, this is known as taking the Open Market Option (OMO). It's important to remember that not all companies offer the same annuity options, and different companies provide different annuity rates.

Allow yourself time to look at all the deals on offer before you commit to buying an annuity product.

Using a reputable independent broker such as Retirement Line could be a good place to start, as they use the whole of the market to help you find the best annuity option for you and your circumstances.

\section{Form a firm exit strategy}

You've worked hard to build up your pension savings and what you do with them in retirement could mean the difference between living a comfortable life and struggling financially.
The NHS pension scheme is a particularly complex area due to the different sections and scheme rules in place, and it can be difficult to understand its worth.

There can be quite substantial taxes on your total pension savings if certain limits are exceeded, particularly with lifetime and annual allowances changes.

An exit strategy for your career is daunting and financially challenging. If you're a business owner, the sale of a dental practice can often take up to two years to complete. Following this, many dentists now are contracted by the new buyer to stay on at the practice for a period of time after the sale. Your strategy here will significantly impact your timeline for exiting the profession and enjoying a well-earned retirement.

Discussing your goals with a financial consultant who has experience in the dental industry will help you navigate these particular issues, ensuring you get the most reliable and considered advice based on experience in your specific career path.

\section{Things you might want to ask a regulated financial consultant}

- Which pension option or options would best suit you and your circumstances?

- What is the difference between a defined benefit pension and a defined contribution?

- What happens if you breach either the Lifetime or Annual Allowance?

- What happens to your pension in the event of your death?

- How might your Income Tax position be affected if you carry on working once you're receiving your pension benefits?

Regularly reviewing your retirement plan with a consultant who understands your history throughout your lifetime will help you keep on track and make necessary adjustments to help you reach your goals.

If you're interested in booking a no-obligation 30-minute Quickstart meeting with one of Wesleyan's specialist Financial Consultants, visit www.wesleyan.co.uk/quickstartBDJ or call 0800 3163784 quoting 1002754 .

\section{About Stephen and the Wesleyan Group \\ Stephen Barry has worked at Wesleyan Financial Services for over 11 years and previously worked at Colgate.}

The Wesleyan Group has had the interests of its members at its core since it was founded with Wesleyan Assurance Society in Birmingham in 1841. In recent years, it has developed a highly successful business model providing tailored financial advice and products to dentists, GPs, hospital doctors, teachers and lawyers and a range of commercial financial products for the organisations in which they are employed.

Charges for advice and services may apply. Advice is provided by Wesleyan Financial Services Ltd. 